\section{An Evaluation of the McClure and Wheeler Optical Calipers}

\author{
by Wallace C. Robbins and Harold E. Young
}

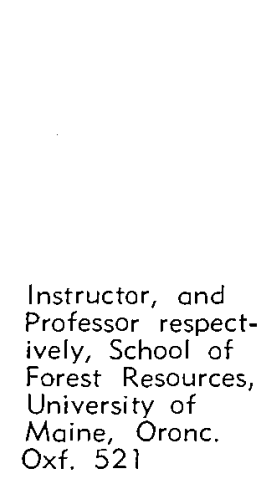

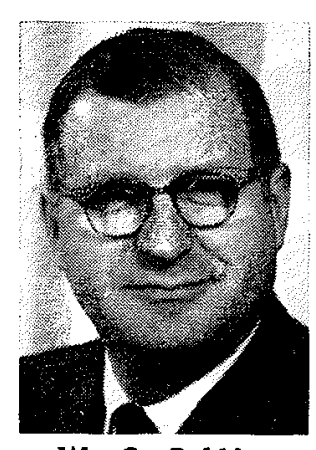

W. C. Robbins

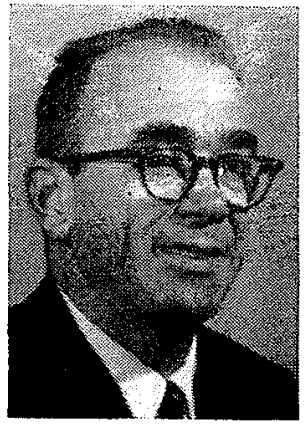

H. E. Young

\begin{abstract}
Five trees of each of four species were measured at six positions on the bole ranging from 0.5 to 32.5 feet above ground with the McClure optical calipers, Wheeler optical calipers, diameter tape and conventional calipers. Measurements are quiclcly and easily made with the optical calipers. The only statistically significant difference occurred at the three middle positions where the $M c$ Clure measurements were larger than the other instruments'. The exact cause for this is not known but it is attributed to the 0.5-inch scale markings on the McClure requiring interpolation to read to 0.1 inch, as there were no significant differences between the instruments when all po-
\end{abstract} sitions were combined in a single analysis.

Foresters are expressing increased interest in accurate upper stem diameter measurements. Grosenbaugh (1963) demonstrated the accuracy of the Barr and Stroud dendrometer which now costs approximately $\$ 3000$. Recently Joseph McClure and Philip Wheeler have each developed hand-held optical calipers to measure stem diameters at any convenient distance from a tree. These cost more than conventional instruments used at breast height, but only a fraction of the cost of the Barr and Stroud. This report will present the results of a field evaluation of the two optical calipers to partially answer questions that many people have raised concerning their accuracy and use in the field.

The Wheeler optical caliper (1962) is based on two pentaprisms, one fixed and the other movable, in a rectangular case with the length of the instrument based on the largest diameter to be measured. To measure the stem diameter, the operator looks both into and over the left prism. He sees the left side of the tree over the prism and aligns the right side of the tree, as seen in the prism, with the left side by moving the right prism within the case toward or away from the left prism. When alignment occurs, the operator reads the scale on the backside of the instrument at the indicator for the stem diameter. A lens can be attached to the Wheeler to increase magnification thereby providing more refined images.

McClure (1967) described his instrument (figure 1) as follows:

“. . . a hand-held optical dendrometer weighing approximately three pounds when fully equipped with all attachments. It is constructed by mounting two strips of first-surface mirror in parallel and facing one another. A sliding scale with a peephole affixed to one end is mounted between the two mirrors.

"Two parallel lines-of-sight are generated by looking into and over the front mirror. The reflected image of a tree's bole is offset to the left. A direct reading of diameter is made at the point a perfect split-image is obtained. The width between the two parallel lines-of-sight is varied by the angle at which the direct line-of-sight strikes the front mirror. The scale is calibrated to the caliper based on the distance between mirrors and distance from the mirrors to the scale."

It is important to note that the scale on the Wheeler permitted direct reading to 0.1 inches whereas the scale on the McClure only permitted direct reading to 0.5 inches necessitating ocular estimating to measure to 0.1 inch. Both instruments were built to measure up to and including 16 inches.

Five red pines, five white pines, five hemlock and five spruce trees were selected in plantations and natural stands within the University Forest, Stillwater, Maine for the study. The six measurement 
positions on each tree were determined by placing a calibrated sectional pole beside the tree. A sectional tree-climbing ladder and pruning saw were used to reach and make conventional caliper and diameter tape measurements at each position. Each position was marked with tree marking paint on the side from which the optical measurements would be made. The conventional caliper measurements at each position were made with the caliper arms parallel to the line of sight that would be used with the optical calipers.

Table 1 shows the measuring positions, the range of diameters at each position and the range of differences between measurements by the optical calipers and the diameter tape with measurements by conventional calipers. Note that the Wheeler was tested with and without a four-power magnifying lens. Table 2 shows the average difference between the measurements by the optical calipers and the diameter tape with measurements by conventional calipers. Physical measurements were made on the first 15 trees before measuring with the optical calipers and last on the remaining five trees.

Initially the measurements were analyzed in the two groups to determine if measurement by the optical calipers had been influenced by physical measurements. No such influence was apparent, so the measurements of all 20 trees were combined for analytical purposes. In the statistical analysis of the measurements at each position, the McClure measurements were significantly larger at $8.5,16.5$, and 24.5 feet above the ground, but when all positions were combined, there were no significant differences between the measurements by the instruments tested. No exact reason for the significant differences in the three middle positions has been established, but tentatively it is attributed to the scale on the McClure which forced ocular estimation to record diameter to 0.1 inch for comparison with the other instruments.

The learning period for the McClure and Wheeler optical calipers is an hour or less. However, it takes several days of continuous use comparing measurements made with the optical calipers to measurements with conventional calipers to become confident in the optical calipers. A single measurement with either optical calipers at any elevation on the tree bole takes approximately 30 seconds.

Table 1

RANGE OF VARIATION IN INCHES BETWEEN CONVENTIONAL CALIPER MEASUREMENTS AND MEASUREMENTS BY OPTICAL CALIPERS, AND THE DIAMETER TAPE, AT VARIOUS POSITIONS ON 20 TREES REPRESENTING FOUR SPECIES.

\begin{tabular}{cccccc}
$\begin{array}{c}\text { Height above } \\
\text { ground }\end{array}$ & $\begin{array}{c}\text { Diameter range } \\
\text { of } 20 \text { trees }\end{array}$ & DT - CC & Mc - CC & W $-\mathrm{CC}$ & W/1 - CC \\
\hline 0.5 & $9.7-16.8$ & -0.7 to 1.5 & -0.5 to 0.7 & -0.4 to 1.0 & -0.6 to 1.5 \\
4.5 & $7.3-15.1$ & -0.4 to 0.6 & -03 to 0.7 & -0.2 to 0.8 & -0.2 to 0.5 \\
8.5 & $6.9-13.9$ & -0.3 to 0.6 & -0.1 to 0.7 & -0.2 to 0.5 & -0.1 to 0.4 \\
16.5 & $6.5-12.2$ & -0.2 to 0.8 & -0.1 to 0.8 & -0.4 to 0.5 & -0.3 to 0.8 \\
24.5 & $5.9-11.3$ & -0.4 to 0.5 & -0.7 to 0.6 & -0.8 to 0.4 & -0.7 to 0.6 \\
32.5 & $4.1-10.3$ & -0.4 to 0.3 & -0.6 to 0.5 & -0.5 to 0.5 & -0.6 to 0.3 \\
all positions & $4.1-16.8$ & -0.7 to 1.3 & -0.7 to 0.8 & -0.8 to 1.0 & -0.7 to 1.5 \\
\hline
\end{tabular}
DT $=$ Diameter Tape.
$\mathrm{W}=$ Wheeler
$\mathrm{CC}=$ Conventional calipers
$\mathrm{Mc}=\mathrm{McClure}$
Wh $/ 1=$ Wheeler with lens

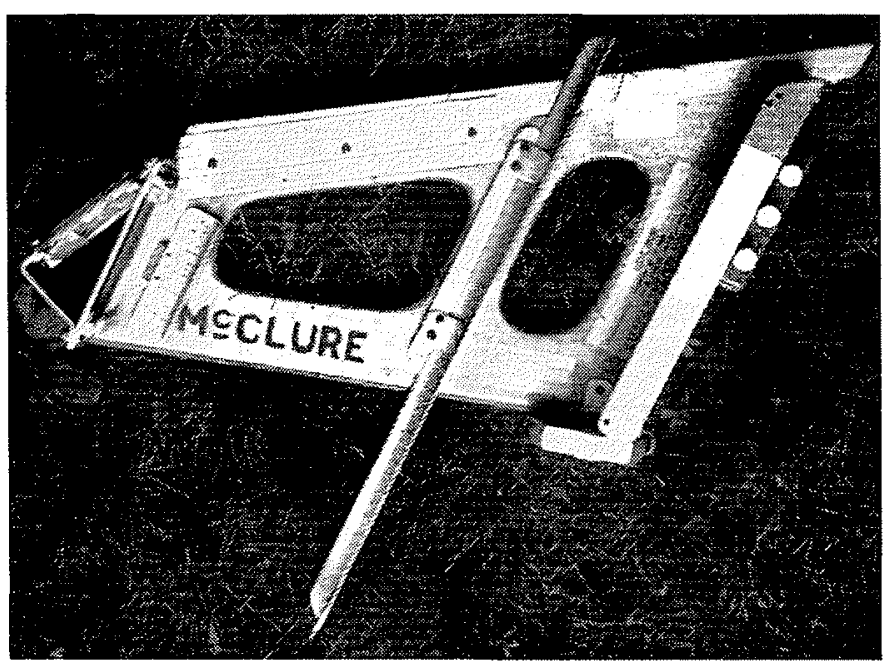

Figure 1 - The McClure optical caliper.

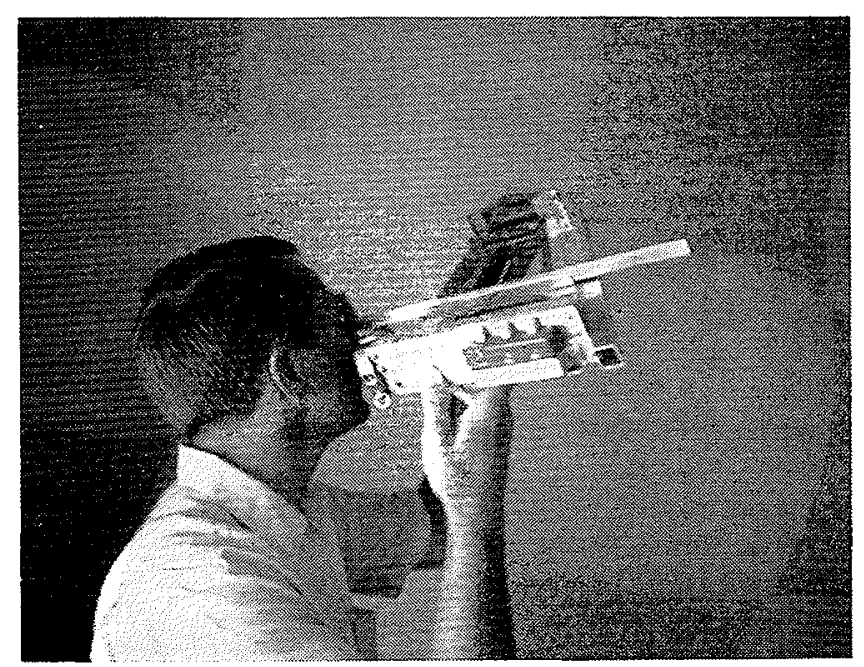

The McClure optical caliper in use 
Table 2

AVERAGE DIFFERENCE IN INCHES, BETWEEN CONVENTIONAL CALIPER MEASUREMENTS AND MEASUREMENTS BY OPTICAL CALIPER, AND THE DIAMETER TAPE.

\begin{tabular}{lccccccc} 
& \multicolumn{6}{c}{ Position height above ground } \\
\cline { 2 - 7 } \multicolumn{1}{r}{ Instrument } & 0.5 & 4.5 & 8.5 & 16.5 & 24.5 & 32.5 \\
\hline Diameter Tape & 0.11 & 0.13 & 0.20 & 0.12 & 0.04 & 0.02 \\
MeClure & 0.06 & 0.26 & 0.32 & 0.30 & 0.14 & 0.13 \\
Wheeler & 0.23 & 0.19 & 0.11 & 0.13 & -0.06 & 0.03 \\
Wheeler with lens & 0.17 & 0.14 & 0.18 & 0.08 & -0.08 & 0.03
\end{tabular}

Conventional wooden calipers were used as the basis for comparison rather than the diameter tape because they are the logical comparison for optical calipers. The diameter tape measurements were included to find out if the differences between such measurements and conventional calipers were similar to differences between the optical calipers and conventional calipers. Tables 1 and 2 show that the differences are similar in magnitude with the only statistical difference occurring with the McClure, as stated earlier. In this study there was no statistically significant difference when using the Wheeler with the lens as compared to using the

\section{Bibliography}

GROSENBAUGH, L. R. 1963. Optical dendrometers for out-of-reach diameters: A conspectus and some new theory. Forest Science Monograph No. 4.
Wheeler without the lens. The gain in magnification as indicated by Grosenbaugh (1963) did not appear and this may be due to a combination of error in hand-held instruments, plus limited magnification.

Conventional calipers are firmly placed on the opposite sides of a tree. When the optical calipers are used, the sides of the tree appear a bit fuzzy due to rough bark which may account for the generally larger measurements of the optical calipers over the conventional calipers. When the McClure scale is calibrated to 0.1 inch, it is likely that measurements with this instrument will not differ significantly from the others to which it was compared in this study.

Future studies are contemplated in which the McClure and Wheeler calipers will be securely fixed to a tripod. Measurements taken in this fashion will be compared to measurements made when the instruments are hand-held to estimate the error attributable to hand-held instruments. As part of such studies, measurements will also be made with a Barr and Stroud dendrometer to determine the differences between the measurements made by the Wheeler and the McClure optical calipers when mounted on a tripod and the measurements made by the Barr and Stroud dendrometer, which is always mounted on a tripod.

MCCLURE, J. P. 1967. Unpublished mimeographed notes on the McClure optical caliper.

WHEELER, P. R. 1962. Penta-prism calipers for upper stem diameter measurements. Jour. For. 60: 877-878.

\section{CANADIAN FORESTRY EDUCATION}

To the man interested in Forestry as a career, Canadian schools offer education at all levels.

\section{Professional Training}

The four University Forestry Faculties, listed below, offer instruction aimed at understanding of fundamental forestry principles, and training in courses of an applied nature best suited to the needs of the forest regions they serve. Opportunities for post-graduate study are also available at the following: -

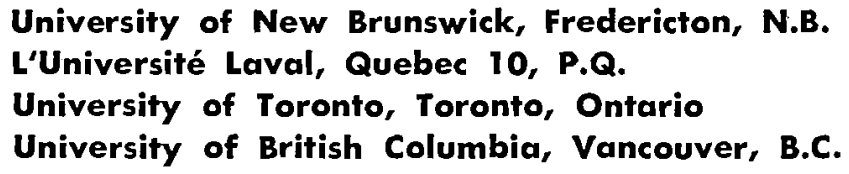

Technological and Vocational Training

These courses are designed to provide men with an adequate knowledge of the theory and practice of Forestry, Logging and Milling so that they may, with adequate on-the-job-experience, serve as an intelligent line of communication and action between the professional forester and the forest labourer.

Two year courses in Forest Technology are offered by: -

British Columbia Institute of Technology, Burnaby, B.C.

Cambrian College, Sault Ste. Marie, Ont.

Lakehead University, Port Arthur, Ont.

Nfld. College of Trades and Technology, St. John's, Nfld.

Northern Alberta Institute of Technology, Edmonton, Alta.

Saskatchewan Technical Institute, Saskatoon, Sask.

Sir Sandford Fleming College, Lindsay, Ontario.

One year courses of technical training in Forestry are offered at the following schools: -

B.C. Forest Training School, North Surrey, B.C.

L'Ecole Forestière de Duchesnay, Québec, P.Q.

Maritime Forest Ranger School, Fredericton, N.B.

Ontario Forest Technical School, Dorset, Ontario.

The B.C. and Ontario schools are limited to in-service training.

For information regarding entrance requirements, courses of study, field training or facilities for specialization at any of the above, please write directly to the school in questions. 